\title{
Mental Health Professionals' Attitudes Towards People with Severe Mental IIIness: Are they Related to Professional Quality of Life?
}

\author{
Katerina Koutra ${ }^{1} \cdot$ Georgios Mavroeides ${ }^{1} \cdot$ Sofia Triliva ${ }^{1}$
}

Received: 31 March 2021 / Accepted: 5 July 2021 / Published online: 12 July 2021

(c) The Author(s), under exclusive licence to Springer Science+Business Media, LLC, part of Springer Nature 2021

\begin{abstract}
The present study examines whether attitudes of mental health professionals (MHPs) towards severe mental illness are associated with professional quality of life. The Attitudes towards Severe Mental Illness (ASMI), the Maslach Burnout Inventory (MBI), and the Professional Quality of Life Scale-5 (ProQOL-5) were completed by 287 MHPs in Greece (25.4\% males, $74.6 \%$ females). The results indicate that MHPs hold predominantly positive attitudes towards people with severe mental illness. Nonetheless, MHPs' attitudes are deemed to be stereotypical according to ASMI concerning treatment duration, prospects of recovery, and whether patients are similar to other people. Higher scores in emotional exhaustion, depersonalization, compassion fatigue and ProQOL-5 burn out dimension were significantly associated with MHPs' unfavorable attitudes, whereas higher scores in compassion satisfaction and personal accomplishment were associated with MHPs' positive attitudes. Assessing compassion fatigue, compassion satisfaction and burnout levels could help identify the processes involved in the development or maintenance of MHPs' stigmatizing attitudes.
\end{abstract}

Keywords Mental health professionals · Attitudes towards severe mental illness · Burnout · Compassion satisfaction · Compassion fatigue

\section{Introduction}

Globally, more than $70 \%$ of people with mental illness do not receive treatment (Thornicroft, 2007). Stigma is considered an influential factor contributing to low help-seeking and high dropout rates among service users with mental illness (Clement et al., 2014; Rüsch et al., 2005). Stigmatizing attitudes towards people with mental illness are often held by the general public (Parcesepe \& Cabassa, 2012; Zolezzi et al., 2018), by people facing mental health challenges themselves (Corrigan \& Rao, 2012), and by mental health professionals (MHPs) (de Jacq et al., 2016; Schulze, 2007; Wahl \& Aroesty-Cohen, 2010). Stigmatization can bring to bear an array of destructive impacts on people facing the serious challenges of mental health problems (Świtaj et al., 2016).

Katerina Koutra

koutra.k@gmail.com; kkoutra@uoc.gr

1 Department of Psychology, School of Social Sciences, University of Crete, Gallos Campus, 74100 Rethymno, Crete, Greece

\section{MHPs' Attitudes Towards Severe Mental IIIness}

Although MHPs have extensive training and experience on mental health issues, they do not always endorse positive views about people with severe mental illness (Lebowitz \& Ahn, 2014; Reavley et al., 2013; Smith et al., 2017). Recent systematic reviews (de Jacq et al., 2016; Schulze, 2007; Wahl \& Aroesty-Cohen, 2010) suggest that MHPs have mixed attitudes towards mental illness, which are comparable to those of the general public. Negative attitudes were more likely to be directed toward persons with schizophrenia (Valery \& Prouteau, 2020). As a result of MHPs stigmatizing attitudes and behavior, people diagnosed with mental illness commonly report feeling dehumanized (Fontesse et al., 2019), devalued, and discriminated against by MHPs. Such perceived experiences can aggravate help-seeking, prolong distress, and compromise patient-professional relationship (Hamilton et al., 2016). Furthermore, MHPs' stigmatizing attitudes towards service users diminish treatment outcomes and contribute to suboptimal health care (van Boekel et al., 2013).

Along with individual factors contributing to MHPs attitudes towards mental illness, such as empathy levels 
(Economou et al., 2019) and personality traits (Solmi et al., 2020), work environment and practice-related factors may also play a significant role in service provision. Specifically, practice-related factors such as the length of practice (Hsiao et al., 2015; Stuber et al., 2014), work setting (Hsiao et al., 2015; Linden \& Kavanagh, 2011), and the type of mental health profession (Lebowitz \& Ahn, 2014; Reavley et al., 2013; Smith et al., 2017) appear to be associated with MHPs stigmatizing attitudes towards service users. Moreover, a qualitative study by Flanagan et al. (2009) showed that stigma in mental health settings may be due to structural, systemic pressures on practitioners (i.e. pressure to "treat the chart" instead of the individual patient and his or her strengths), and practitioners' emphasis on symptoms, deficits, and compliance as secondary factors. In two parallel focus group studies focusing respectively on MHPs and service users in six European countries (Belgium, Cyprus, Greece, the Netherlands, Norway and Sweden), MHPs attributed the gaps to service provision to similar structural and systemic barriers. The MHPs described how insufficient funding, human resources, and availability of appropriate treatments render mental healthcare inaccessible (Triliva et al., 2020). Similarly, service users related difficulties in obtaining care, treatment tailored to their needs, and respect and recognition for their potential (Axelsson et al., 2020).

\section{Professional Quality of Life in MHPs}

Professional quality of life, by definition, includes both positive and negative dimensions at the individual, organizational, and societal levels that influence the well-being and effectiveness of professionals (Stamm, 2002). Both the rewarding (i.e. compassion satisfaction) and deleterious (i.e. compassion fatigue) aspects alike are critical to understanding the impact of working with mental illness for MHPs. Compassion satisfaction is a term used to describe the sense of fulfillment or pleasure that therapists derive from doing their work well (Stamm, 2002, 2005). Compassion satisfaction is made up of three elements: (i) the level of satisfaction that a person derives from his/her job; (ii) how well a person feels he/she is doing in his/her job, related to the levels of competency and control that therapists feel they have over the traumatic material they are exposed to; and (iii) the level of positive collegial support provided to MHPs, with aspects of structural and functional social support being particularly important (Stamm, 2002). On the contrary, compassion fatigue is a term coined by Figley $(1995$, p. 9) and refers to the "cost of caring" that is characterized by physical and emotional exhaustion and a diminished ability to empathize. According to the systematic review by Singh et al. (2020), 19.8\% of MHPs report compassion fatigue to some degree. Moreover, recent studies show that $10-74.1 \%$ of MHPs are affected by compassion fatigue (Laverdière et al., 2019; Xie et al., 2020). Compassion fatigue may have numerous implications for care-giving professionals' health and wellbeing (e.g., behavioral, cognitive, physical health, emotional) (Bride et al., 2007; Figley, 2002). For example, compassion fatigue levels are consistently associated with secondary Post Traumatic Stress Disorder (PTSD) symptoms among MHPs (Lauvrud et al., 2009; Ray et al., 2013; Tirgari et al., 2018).

Burnout has found to be most common in health-service and public-service related fields, specifically within mental health care (Awa et al., 2010), and constitutes a leading cause of work-related problems for MHPs (Baker, 2003; Bearse et al., 2013; Lee et al., 2011; O'Connor et al., 2018). The term "burnout" was coined in the 1970s by the American psychologist Herbert Freudenberger, who used it to describe the consequences of severe stress and high ideals in "helping" professions (Freudenberger, 1974). One of the most prominent definitions describes burnout "as a syndrome of emotional exhaustion, depersonalization, and reduced personal accomplishment that can occur among individuals who work with people in some capacity" (Maslach et al., 1996, p. 4). Emotional exhaustion occurs as a result of one's emotional demands. Depersonalization refers to a cynical, negative or detached response to care recipients. The reduced personal accomplishment refers to a belief that one can no longer work effectively with healthcare recipients (Stalker $\&$ Harvey, 2002). The prevalence of burnout among MHPs has been estimated at between 21 and 67\% (Morse et al., 2012), while recent findings concerning the prevalence of burnout among North American psychiatrists indicated high levels of burnout in $78 \%$ of the participants (Summers et al., 2020). Furthermore, a recent systematic review and metaanalysis (O'Connor et al., 2018) also found high rates of burnout among MHPs. Specifically, the overall estimated pooled prevalence for emotional exhaustion was $40 \%$, for depersonalization was $22 \%$, and for low levels of personal accomplishment was $19 \%$. These results showed that the average MHP has high levels of emotional exhaustion, moderate levels of depersonalization but retains reasonable levels of personal accomplishment (O'Connor et al., 2018).

\section{The Greek Mental Health System}

The mental healthcare system in Greece has been undergoing reforms for the past two decades driven by funding from the Psychargos program. Services have moved away from institutional care towards community-based mental health care. Various forms of community-based mental health services have been developed including supported living facilities, community mental health centers and employment opportunities (Christodoulou et al., 2012). Nevertheless, health services in the country were profoundly impacted by the socioeconomic crisis of 2008-2018 by budget cuts and 
reductions to access (Triliva et al., 2013) and increases in referrals and demand for services (Kyriakidou \& Triliva, 2018). A comprehensive framework for mental healthcare provision has not been established in Greece, and this is not an exception concerning mental health stigma and its effects. In a recent study, MHPs in the country were predominantly favorable towards people with severe mental illness. Still, unfavorable attitudes about people with a mental illness diagnosis included pessimism about recovery, viewing them as deviant and keeping a distance in close social interactions (Economou et al., 2019).

Burnout and compassion fatigue are prevalent in Greek MHPs. Specifically, according to a study by Mangoulia et al. (2015) focusing on a sample of 174 psychiatric nurses, $49.4 \%$ of their participants were at high risk for burnout and $44.8 \%$ for compassion fatigue. Furthermore, in a very recent study of 78 mental health nurses, Konstantinou et al. (2018) reported that $53.8 \%$ of the participants disclosed high levels of emotional exhaustion and $24.4 \%$ depersonalization levels. Finally, a much higher prevalence of burnout was reported in a study concerning 180 Greek MHPs working in a substance abuse treatment facility, since $75 \%$ of the participants had high levels of emotional exhaustion, $71 \%$ had high levels of depersonalization, and $75 \%$ had low levels of personal accomplishment (Rachiotis et al., 2020).

\section{The Present Study}

Limited previous studies have focused separately on the links between burnout and stigma among MHPs (Holmqvist \& Jeanneau, 2006; Solmi et al., 2020; Zaninotto et al., 2018). In the study by Holmqvist and Jeanneau (2006) all three burnout dimensions were correlated with MHPs' negative feelings toward people with a severe mental illness. More recent findings suggest that a lower level of personal accomplishment was associated with avoidant attitudes toward service users (Zaninotto et al., 2018). Furthermore, higher levels of burnout in terms of low personal accomplishment were associated with more negative views about people with severe mental illness, particularly in those MHPs showing lower emotional stability (Solmi et al., 2020). To the best of our knowledge, no previous research has focused on compassion fatigue and compassion satisfaction concerning MHPs' attitudes towards mental illness. The cumulative effects of professional quality of life dimensions on MHPs' attitudes have not been investigated. Mental healthcare intrinsic characteristics further compound any personal stress MHPs experience, since they often confront additional emotional strain due to the nature of their work with distressed individuals (Cetrano et al., 2017).

Given the complexities outlined above, the present study focused on investigating the association between professional quality of life and attitudes towards mental illness of MHPs in Greece. We hypothesized that higher levels of emotional exhaustion, depersonalization, burnout, and compassion fatigue would be associated with unfavorable attitudes. In contrast, higher personal accomplishment levels and compassion satisfaction would be related to more positive attitudes towards mental illness. These aspects were selected as key variables in our study as they may be a potential threat to MHPs' wellbeing and, consequently, the quality of care provided.

\section{Methods}

\section{Participants}

This was a cross-sectional study and sample size estimation was based on medium expected effect sizes, according to Cohen's criteria (Cohen, 1988), for power 0.80 and confidence level 0.05 . Hence, a total of 287 MHPs participated in the study (response rate $87.0 \%$ ). Inclusion criteria included being: (i) between 22 and 67 years of age, (ii) a MHP (i.e. psychiatrist, psychologist, social worker, speech therapist, occupational therapist, etc.) currently employed in the public or private sector, and (iii) able to understand the Greek language. Participants working on a volunteer basis and administrative personnel were excluded from the sample. Data were collected between October 2019 and April 2020.

Community mental health staff from various regional units (i.e. Attica, Central Macedonia, Thessaly, Peloponnese and Crete), was invited to participate in the survey in person or via online advertisements and invitations. In the first case, individuals were administered the questionnaires in their workplace by trained research assistants. In the second case, they could follow a link and take part in the survey online. In both cases, participants were thoroughly informed about the research's purpose and were reassured about the researchers' ethical responsibility to uphold the principle of anonymity and confidentiality. The participation was voluntary, and there were no consequences in case of refusal or dropping out. Also, participants were given written instructions for filling out the questionnaires and were informed about the estimated time needed for completing the measures (approximately 15-20 min). Written informed consent was obtained from all participants. The study was conducted in accordance with the ethical standards delineated in the Declaration of Helsinki. Ethical approval was granted by the University of Crete's Research Ethics Committee.

\section{Measures}

\section{Socio-Demographic and Professional Characteristics}

The following demographic and professional information were collected from participants: age, gender (male, female), nationality (Greek, other), educational attainment 
(diploma certificate, higher education), marital status (single, married, divorced/widowed), place of origin (urban, semi-urban, rural), place of residence (urban, semi-urban, rural), professional group (psychiatrist, psychologist, social worker, nurse, others, i.e. occupational therapists, General Practitioners, counsellors, etc.), years of work experience, public/private sector, and personal income (low, medium, high, very high).

\section{Attitudes Towards Severe Mental IIIness (ASMI; Madianos et al., 2012)}

Participants' attitudes towards people with mental illness was assessed by the Greek ASMI scale (Madianos et al., 2012), which includes 30 items in the form of statements. The scale has four dimensions: (i) Stereotyping (factor A) consists of 11 items addressing commonly espoused negative conceptions of severe mental illness, (ii) Optimism (factor B) encompasses six items addressing positive beliefs and attitudes about severe mental illness and patients, (iii) Coping (factor $\mathrm{C}$ ) entails seven items reflecting coping strategies and the stigma associated with mental illness, and (iv) Understanding (factor D) includes six items addressing the extent to which the respondents can place themselves in the patients' shoes. The ASMI is rated at a 5-point Likert scale indicating the individual's agreement or not in each item. For Factors B, C, and D agreement implies non-stigmatizing opinions and attitudes. Conversely, agreement with the items of Factor A implies stereotypical beliefs and unfavorable attitudes. As a result of this, Factor A items were reversely scored. In line with this, higher scores for all factors indicated non-stigmatizing attitudes and opinions. The scale has proved to have adequate psychometric properties (Madianos et al., 2012). In the current study, the ASMI demonstrated good internal consistency; Cronbach's $\alpha$ coefficient was found to be 0.79 for Stereotypes, 0.73 for Optimism, 0.63 for Coping, and 0.79 for Understanding. Similarly, to the study of Economou et al. (2019), for computing the total scale score, the factor Understanding was excluded: Cronbach's $\alpha=0.60$ with the factor and Cronbach's $\alpha=0.69$ without the factor.

\section{Maslach Burnout Inventory (MBI; Maslach \& Jackson, 1981)}

The Maslach Burnout Inventory (MBI; Maslach \& Jackson, 1981 ) is the most widely used measure for assessing burnout. The MBI includes three burnout dimensions: (i) Emotional Exhaustion contains nine items and describes feelings of being emotionally exhausted because of the work), (ii) Depersonalization consists of five items and describes detached and impersonal treatment of patients, and (iii) Personal Accomplishment contains eight items that describe beliefs of competence and achievement at work (Evans et al.,
2006). Each of the 22 items asks individuals to describe their feelings on a 7-point scale, ranging from never having those feelings to having those feelings a few times a week. Higher scores for Emotional Exhaustion and Depersonalization and a lower score for Personal Accomplishment indicate a high tendency for burnout. Cronbach's $\alpha$ coefficient for each dimension was as follows: 0.84 for Emotional Exhaustion, 0.81 for Depersonalization, and 0.83 for Personal Accomplishment.

\section{Professional Quality of Life Scale-5 (ProQOL-5; Stamm, 2010)}

The Professional Quality of Life Scale-5 (ProQOL-5) is the most commonly used measure of the positive and negative effects of working with people who have experienced extremely stressful experiences. The ProQOL consists of 30 items measuring facets of compassion satisfaction and compassion fatigue, targeted at individuals working in caring or helping professions (Stamm, 2010). The ProQOL contains three subscales measuring Compassion Fatigue, Burnout and Compassion Satisfaction. Each subscale is unique, and the scales' results cannot be combined to give a single meaningful score. The instrument includes 30 items, ten on each scale, rated numerically on a 5-point Likert scale, ranging from 0 (never) to 5 (very often). Higher scores on the Compassion Fatigue subscale indicate the respondent is at higher risk for compassion fatigue. Higher scores on the burnout subscale indicate that the individual is at risk of experiencing burnout symptoms (e.g., hopelessness, helplessness) (Stamm, 2010). Higher scores on the Compassion Satisfaction subscale indicate the respondent is experiencing better satisfaction with his or her ability to provide care (e.g., caregiving is an energy-enhancing experience, increased self-efficacy). Compared to the scale structure reported by Stamm (2010), we similarly found good alpha reliabilities for the Burnout $(\mathrm{a}=0.78)$, Compassion Fatigue $(\mathrm{a}=0.76)$, and Compassion Satisfaction $(\mathrm{a}=0.90)$ scales.

\section{Statistical Analyses}

Descriptive statistics were used to summarize the characteristics of the sample. Frequencies were computed for nominal and ordinal variables and mean and standard deviations for numeric variables. Internal consistency of the scales was evaluated with Cronbach's $\alpha$ coefficient. In order to identify the sociodemographic and professional predictors of attitudes to severe mental illness and professional quality of life, univariate analyses were initially performed: t-test, one-way ANOVA and Pearson correlation. Multivariable linear regression models were fit to estimate the associations between attitudes towards mental illness, burn out dimensions and professional quality of life after adjusting 
for confounders. Variables that were found to exert a statistically significant effect on the independent variables (burn out dimensions and professional quality of life) and/ or dependent variables (attitudes towards mental illness) at p-value $<0.2$ were entered simultaneously as confounders in a multiple linear regression model. Therefore, potential confounding variables included sociodemographic (i.e., gender, age, educational level) and professional (i.e., specialization, public/private unit, years of work experience) characteristics. Separate multivariable models were built having as an outcome each subscale of the ASMI. Estimated associations are described in terms of $\beta$-coefficients (beta) and their $95 \%$ confidence intervals (CI). All hypothesis testing was conducted assuming a 0.05 significance level and a two-sided alternative hypothesis. All statistical analyses were performed using SPSS Statistics 26 software (IBM, Armonk, NY, USA).

\section{Results}

\section{Socio-Demographic and Professional Characteristics}

The sample comprised 73 (25.4\%) males and 216 (74.6\%) females. Participants' mean age was $39.85 \pm 9.52$ years, with that of male and female participants being $42.30 \pm 10.12$ years and $38.98 \pm 9.17$ years, respectively. Male participants' mean age was significantly higher than that of female participants $(\mathrm{p}<0.05)$. The vast majority of the sample came from and was residents of urban areas (83.6\% and $95.1 \%$, respectively). Almost half of the sample was married. Most respondents had either completed undergraduate studies in a university or a technical higher education institution (93.0\%). Regarding personal income levels, the majority of participants classified their income as either medium (40.4\%) or high (41.1\%). Half of the participants had more than 10 years of experience working in the mental health field. There were 98 (34.1\%) psychologists, 56 (19.5\%) psychiatrists, 43 (15.0\%) social workers, 47 (16.4\%) mental health nurses, and 43 (15.0\%) other mental health professionals (i.e. occupational therapists, General Practitioners, counsellors, etc.) who participated in the study. Finally, $62.4 \%$ of the participants worked in public and $37.6 \%$ in the private sector. Sample characteristics are presented in Table 1.

\section{Descriptive Statistics for MHPs' Attitudes Towards People with Mental IIIness and Associations with Socio-Demographic Characteristics}

MHPs held predominantly positive attitudes towards people with severe mental illness. There was only one instance where participants appeared to be divided, and it was focused broadly on their attitudes about treatment duration. Specifically, almost $40 \%$ of the sample agreed (agree/rather agree) with the item "People with severe mental illness have to take medication the rest of their lives". In a similar vein, $26.5 \%$ of participants agreed (agree/rather agree) with the item that "Severe mental illness makes the person who suffers from it look ill from a distance", and 20.5\% agreed (agree/rather agree) with the item "Once ill, people with severe mental illness stop being like other people". The afore-mentioned items are included in the stereotyping subscale of ASMI which taps endorsement of stereotypical beliefs about severe mental illness. Finally, $25.1 \%$ of participants disagreed (disagree/rather disagree) with the item "People with severe mental illness can recover nowadays". This item is included in the optimism subscale of ASMI which describes positive attitudes about severe mental illness and possible recovery.

Table 1, also, presents the associations of socio-demographic and professional characteristics with MHPs' attitudes towards mental illness (ASMI total score). Participants with university education held less stereotyping attitudes than MHPs with a diploma certificate (2-year training). Nurses and other professionals held more stereotyping beliefs than psychiatrists, psychologists, and social workers.

\section{Bivariate Correlation Between the Study Variables}

Means, standard deviations and the intercorrelations for the major study variables are included in Table 2. All MBI dimensions were correlated with three out of the ASMI subscales: stereotyping, optimism, and coping, as well as total ASMI score. Notably, emotional exhaustion was positively correlated with stereotyping and negatively correlated with optimism and coping. Personal accomplishment was positively correlated with stereotyping, optimism, and coping, while depersonalization was negatively correlated with stereotyping, optimism, and coping. Moreover, the three ProQOL subscales were also correlated with the ASMI subscales, as well as ASMI total score. Specifically, compassion satisfaction was positively correlated with stereotyping, optimism, coping and understanding. Burnout was negatively correlated with stereotyping, optimism, and coping and compassion fatigue was negatively correlated with stereotyping. The MBI and ProQOL subscales were also significantly correlated. Emotional exhaustion was negatively correlated with compassion satisfaction and positively correlated with burn out and compassion fatigue. Personal accomplishment was positively correlated with compassion satisfaction and negatively correlated with burnout and compassion fatigue. Depersonalization was negatively correlated with compassion satisfaction and positively correlated with burnout and compassion fatigue. 
Table 1 Sociodemographic and professional characteristics of participants $(n=287)$ and associations with attitudes towards mental illness

\begin{tabular}{|c|c|c|c|c|}
\hline & $\mathrm{N}$ & $\%$ & ASMI total Mean (SD) & $\mathrm{p}$-value \\
\hline \multicolumn{5}{|l|}{ Gender } \\
\hline Male & 73 & 25.4 & $81.15(12.27)$ & \multirow[t]{2}{*}{0.203} \\
\hline Female & 214 & 74.6 & $82.93(9.53)$ & \\
\hline \multicolumn{5}{|l|}{ Nationality } \\
\hline Greek & 284 & 98.6 & $82.44(10.33)$ & \multirow[t]{2}{*}{0.553} \\
\hline Other & 3 & 1.4 & $86.00(8.66)$ & \\
\hline \multicolumn{5}{|l|}{ Origin } \\
\hline Urban & 240 & 83.6 & $82.25(10.70)$ & \multirow[t]{2}{*}{0.339} \\
\hline Rural & 47 & 16.4 & $83.64(7.99)$ & \\
\hline \multicolumn{5}{|l|}{ Residence } \\
\hline Urban & 273 & 95.1 & $82.59(10.35)$ & \multirow[t]{2}{*}{0.431} \\
\hline Rural & 14 & 4.9 & $80.36(9.32)$ & \\
\hline \multicolumn{5}{|l|}{ Marital status } \\
\hline Unmarried & 121 & 42.2 & $82.55(11.06)$ & \multirow[t]{3}{*}{0.881} \\
\hline Married & 140 & 48.8 & $82.46(9.25)$ & \\
\hline Divorced/widowed & 26 & 9.0 & $82.23(12.31)$ & \\
\hline \multicolumn{5}{|l|}{ Educational attainment } \\
\hline Diploma certificate (2-year training) & 20 & 7.0 & 77.65 (12.34) & \multirow[t]{2}{*}{$\mathbf{0 . 0 3 0}$} \\
\hline Higher education & 267 & 93.0 & $82.84(10.07)$ & \\
\hline \multicolumn{5}{|l|}{ Professional group } \\
\hline Psychiatrist & 56 & 19.5 & $82.61(9.92)$ & \multirow[t]{5}{*}{$<0.001$} \\
\hline Psychologist & 98 & 34.1 & $84.92(7.28)$ & \\
\hline Social worker & 43 & 15.0 & $85.46(7.66)$ & \\
\hline Nurse & 47 & 16.4 & $78.42(12.77)$ & \\
\hline $\begin{array}{l}\text { Other (occupational therapists, general practition- } \\
\text { ers, counsellors, etc.) }\end{array}$ & 43 & 15.0 & $78.18(13.18)$ & \\
\hline \multicolumn{5}{|l|}{ Years of expertise } \\
\hline Up to 5 years & 90 & 31.4 & $82.15(10.82)$ & \multirow[t]{3}{*}{0.835} \\
\hline $5-10$ years & 46 & 16.0 & $81.98(10.22)$ & \\
\hline More than 10 years & 151 & 52.6 & $82.82(10.06)$ & \\
\hline \multicolumn{5}{|l|}{ Professional sector } \\
\hline Public & 179 & 62.4 & $82.76(10.82)$ & \multirow[t]{2}{*}{0.551} \\
\hline Private & 108 & 37.6 & $82.01(9.41)$ & \\
\hline \multicolumn{5}{|l|}{ Personal income } \\
\hline Low & 14 & 4.9 & $85.71(9.70)$ & \multirow[t]{4}{*}{0.419} \\
\hline Medium & 116 & 40.4 & $82.29(11.25)$ & \\
\hline High & 118 & 41.1 & $82.88(9.04)$ & \\
\hline \multirow[t]{2}{*}{ Very high } & 39 & 13.6 & 80.64 (11.16) & \\
\hline & & Mean (SD) & $\mathrm{r}$ & \\
\hline Age (years) & & $39.85(9.52)$ & 0.012 & 0.840 \\
\hline
\end{tabular}

ASMI attitudes towards severe mental illness, $S D$ standard deviation

Bold font indicates statistical significant differences at $\mathrm{p}<0.05$, based on t-test, ANOVA or Pearson $\mathrm{r}$ correlation coefficient

\section{Multivariate Associations Between MHPs' Professional Quality of Life Dimensions and Attitudes Towards Mental IIIness}

The results from the multivariate analysis are presented in Table 3. Gender, age, educational level, specialization, public/ private unit, and years of employment were included in the multivariable models as potential confounders in the relationship between work-life characteristics and attitudes towards mental illness. The results indicated that higher levels of emotional exhaustion were associated with lower scores in stereotyping, optimism and coping subscales, as well as total ASMI 

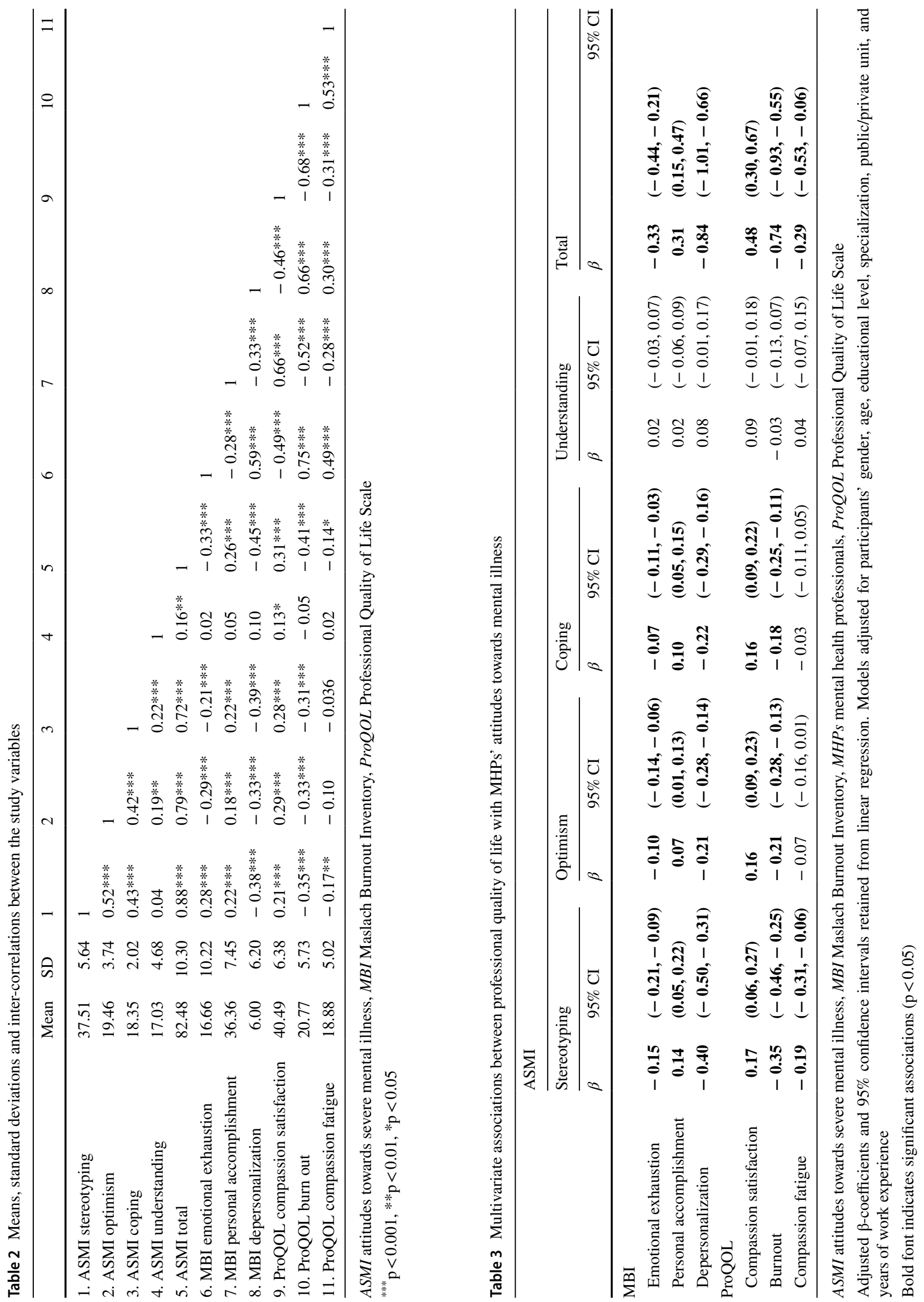
score $(\beta$ coefficient $-0.33,95 \%$ CI $-0.44,-0.21)$. Similarly, higher levels of depersonalization were linked with lower scores in stereotyping, optimism, and coping subscales, and with a 0.84 decrease in total ASMI score $(\beta$ coefficient -0.84 , $95 \%$ CI $-1.01,-0.66)$. Higher levels of personal accomplishment were associated with increased scores in stereotyping, optimism and coping subscales, as well as total ASMI score ( $\beta$ coefficient $0.31,95 \%$ CI $0.15,0.47$ ). Moreover, a higher level of compassion satisfaction was related to increased scores in stereotyping, optimism, coping subscales and total ASMI score ( $\beta$ coefficient $0.48,95 \%$ CI $0.30,0.67)$. Higher scores in ProQOL-5 burnout subscale were linked with lower scores in stereotyping, optimism and coping subscales and with a 0.74 decrease in total ASMI score $(\beta$ coefficient -0.74 , $95 \%$ CI $-0.93,-0.55)$. Finally, a higher level of compassion fatigue was associated with lower scores in stereotyping and total ASMI score ( $\beta$ coefficient $-0.29,95 \%$ CI $-0.55,-0.06$ ).

\section{Discussion}

This study provides some new insights in to how professional quality of life is related to MHPs' attitudes towards people with mental illness. Our findings suggest that indications of emotional exhaustion, depersonalization, compassion fatigue and burnout are linked to negative attitudes towards people with mental illness, whereas increased incidence of personal accomplishment and compassion satisfaction are correlated with positive attitudes.

In our study, MHPs were found to hold favorable attitudes towards people with severe mental illness. However, in some cases, MHPs also hold stereotypical attitudes, mainly concerning the duration of treatment, perceptions of people with a mental illness and how similar they are to others, and regarding prospects for recovery. More specifically, almost $40 \%$ of the sample agreed that people with severe mental illness have to take medication for the rest of their lives. Severe mental illness is an umbrella term used by both researchers and clinicians to categorize the most serious mental disorders (i.e. schizophrenia, bipolar disorder, major depressive disorder and schizoaffective disorder) that share basic characteristics, such as intense symptom severity and severe functional impairment when the condition goes untreated (Whitley et al., 2015). Although lifetime medication is sometimes recommended for patients with severe mental disorders, such as schizophrenia (Glick et al., 2020), a generalized belief that this is the case for all patients with severe mental disorders may also reveal a stereotyping tendency. According to Marder and Zito (2018) nearly all patients ask the question: "Will I need to take these medications for the rest of my life?" and there is only one honest answer to this question, which is "Probably, but I can't be certain", therefore, avoiding absolutes when talking to patients.
Additionally, a smaller but notable proportion of MHPs in our study agreed with the views that severe mental illness makes the person who suffers from it look ill from a distance (26.5\%), and that, despite their concerted efforts, people with severe mental illness will never be like other people (20.5\%). MHPs also disagreed with the view that people with severe mental illness can recover nowadays (25.1\%). According to Anthony (1993), "recovery involves the development of new meaning and purpose in one's life as one grows beyond the catastrophic effects of mental illness (p. 527)". In our study, the term "recovery" is used to describe clinical rather than personal recovery from severe mental illness. More specifically, according to the Remission in Schizophrenia Working Group (Andreasen et al., 2005), "for a disorder such as schizophrenia, complete recovery implies the ability to function in the community, socially and vocationally, as well as being relatively free of disease-related psychopathology (p. 442)". Hence, although personal recovery can indeed be independent of whether individuals continue having psychiatric symptomatology, clinical recovery includes an improvement in patients' functioning and core signs and symptoms. Our findings are consistent with those of a recent study in Greece, which found that MHPs endorsed predominantly favorable attitudes towards people with severe mental illness while concomitantly depicting trepidation and doubt regarding their prospects for clinical recovery (Economou et al., 2019). These findings are also in line with international findings of recent systematic reviews (de Jacq et al., 2016; Schulze, 2007; Wahl \& Aroesty-Cohen, 2010), suggesting that MHPs hold both positive and negative attitudes towards mental illness. According to the literature, stigmatization has a profound and deleterious impact on people facing severe mental health challenges (Świtaj et al., 2016). Moreover, mental health service users feel the brunt of stigmatizing attitudes and behaviors, as well as the systemic obstacles in receiving adequate and sufficient mental healthcare (Axelsson et al., 2020). This stigma cycle breaks down the "chain of care", adds to the mental healthcare gap and diminishes MHPs ability to provide responsive care (Triliva et al., 2020).

Concerning the association of MHPs' background with stigmatizing attitudes towards severe mental illness, our findings indicate that the specialization and educational level are associated with MHPs' attitudes. Specifically, in our sample, social workers and psychologists were found to hold the most favorable attitudes towards people with severe mental illness, while psychiatric nurses and other MHPs (i.e., occupational therapists, General Practitioners, counselors, etc.) held the least favorable attitudes. This finding is consistent with the study by Economou et al. (2020), who also found that psychologists and psychiatric nurses demonstrated the most and the least favorable attitudes towards people with mental illness, respectively. In interpreting this finding, one could assume that differences in MHPs' training and work content and context may be related to their 
attitudes towards individuals with mental illness. Furthermore, in our study, educational level was also connected to MHPs' stigmatizing beliefs since participants with university education held fewer stereotyping attitudes than MHPs with a diploma certificate (2-year training). In a previous study by Ebrahimi et al. (2012), educational level was also associated with stigmatizing attitudes towards mental illness, with MHPs with university education holding significantly fewer stigmatizing attitudes than practical MHPs with lower education. Thus, it appears that a higher level of education may promote awareness about mental illness, reducing MHPs' stigmatizing beliefs about it.

Psychological burnout syndrome, which is marked by feelings of depletion and overwhelming exhaustion, heightened cynicism, detachment, and an inability to feel accomplishment within one's work (Maslach \& Jackson, 1984; Maslach et al., 1986), was found to be associated with MHPs' stigmatizing attitudes towards mental illness. In our sample, high emotional exhaustion and depersonalization were related to stigmatizing attitudes towards people with mental illness, while a high level of personal accomplishment was associated with more favorable attitudes. The results of the present study are consistent with those of recent field research showing that emotional exhaustion, depersonalization, and low personal accomplishment predict the stigmatizing attitudes of MHPs towards people with mental disorders (Holmqvist \& Jeanneau, 2006; Solmi et al., 2020; Zaninotto et al., 2018). In their study, Holmqvist and Jeanneau (2006) showed that MHPs' burnout levels, measured in terms of tedium, emotional exhaustion, depersonalization, and personal accomplishment, were associated with MHPs' feelings towards service users with a mental illness diagnosis. According to their findings, high tedium, emotional exhaustion, and depersonalization were associated with MHPs feeling controlled, unhelpful, rejecting, and distant. Moreover, MHPs who endorse high levels of tedium, emotional exhaustion, and depersonalization also felt less close to service users, less autonomous, less helpful, and less accepting. On the contrary, MHPs high on personal accomplishment felt less controlled, less unhelpful, less rejecting, less distant, more autonomous, more helpful, accepting, and closer to patients. Investigating the combined predictive role of burnout and personality traits in MHPs' attitudes towards their patients, Solmi et al. (2020) found a significant interaction between personal accomplishment and neuroticism in predicting MHPs' stigmatizing attitudes. Specifically, lower personal accomplishment was associated with higher stigmatizing attitudes in MHPs with high neuroticism levels. Moreover, in the study by Zaninotto et al. (2018), MHPs high on emotional exhaustion were less likely to provide support for coercive treatment to patients, while MHPs high on personal accomplishment showed fewer avoidance beliefs towards the patients.

To the best of our knowledge, no previous research had been conducted on compassion fatigue and compassion satisfaction in relation to MHPs' attitudes towards mental illness. Moreover, very limited previous research has investigated compassion satisfaction and compassion fatigue in association with stigma in healthcare professionals in general. Knaak et al. (2019) investigated the association of stigma and compassion satisfaction among healthcare providers and service users, using a qualitative methodology. According to the study results, negative attitudes about addiction, low belief in the possibility of addicted individuals' wellness, burnout, compassion fatigue, and vicarious trauma emerged as key themes, which coalesced around the central theme of low compassion satisfaction (Knaak et al., 2019). Furthermore, low compassion satisfaction has also been linked to affiliate stigma among MHPs, which according to the researchers, may, in turn, lead to MHPs avoiding or discriminating against service users (Joyce \& Blessing, 2019).

Professional quality of life has been established as an important determinant of MPHs' well-being and mental health, since it is associated with outcomes such as MHPs' psychological distress (Adams et al., 2006), their happiness (Mantelou \& Karakasidou, 2019), and the development of posttraumatic symptoms (Ray et al., 2013; Tirgari et al., 2018). In our study, compassion fatigue and compassion satisfaction were found to function as risk and protective factors, respectively, regarding the negative attitudes of MHPs towards mental illness. Hence, adding to the existing literature, this is the first study that links compassion satisfaction and compassion fatigue to outcomes that hold significance for the MHPs and their attitudes towards service users and potentially for the mental health care services they provide.

\section{Strengths and Limitations}

This study's main strength is the relatively large number of participants, from different professional groups, working in varied settings, such as inpatient psychiatric units, outpatient, day, and residential services. In addition, the response rate was high (87\%). A further strength of the study is the inclusion of a large set of variables measuring socio-demographics, occupational characteristics, and a core set of indicators of quality of work-life. The latter made it possible to capture participants' subjective experiences and perceptions about their work-life quality as a whole.

However, some limitations of the study should be taken into account. First, the cross-sectional nature of the survey did not allow the determination of causality. Moreover, although participants from different regions in Greece were included, the study results do not necessarily generalize to the whole country. Furthermore, because this study emphasized the role of organizational and environmental factors, other possible relevant variables (i.e. coping with workrelated stresses) were not included. Future studies could integrate such variables by considering different organizational 
settings and/or by including service users' evaluations of care effectiveness, stigmatization and systemic barriers.

\section{Conclusions}

In conclusion, this study's scientific value lies in its contribution to advancing the comprehensive examination of the nexus of variables involving compassion fatigue, compassion satisfaction, and burnout dimensions (i.e. emotional exhaustion, personal accomplishment and depersonalization) in a large group of MHPs. Results indicate that professional quality of life is associated with MHPs' attitudes towards mental illness. These results suggest a need for interventions specifically designed to enhance professional quality of life in MHPs and support their wellbeing in the Greek mental health workplace. Anti-stigma training focusing on sensitizing MHPs on the impacts of stigma and reducing discriminatory tendencies can be an effective intervention ameliorating stigmatization.

Job satisfaction of MHPs is considered an essential factor in MHPs work-life quality and consequently quality mental healthcare provision. The present study's findings could also be used to design and implement targeted psychosocial interventions to empower MHPs and enhance their job satisfaction. Interventions along these lines should include components that focus on diminishing stigmatizing attitudes. Such programming can play a vital role in the ongoing training and supervision of MHPs, which is considered a crucial mental healthcare component. Based on the findings, future research and practice recommendations to reduce burnout and compassion fatigue are noted. It is crucial to investigate further the dimensions of burnout and the quality of professional life related to stigmatizing attitudes towards people with a mental illness diagnosis using prospective or longitudinal studies. By establishing a better understanding of burnout's processes and interrelationships with compassion fatigue and stigmatization, targeted interventions can be designed to ameliorate the debilitating impacts of these factors for MHPs, service users, and mental healthcare provision.

Acknowledgements We are very grateful to all participants of the study.

Funding This study is part of the research project entitled 'Mental health professionals' attitudes toward mental healthcare: associations with work satisfaction indices' funded by Small Scale Project of the Special Account for Research, University of Crete, Greece. Reference number: 10635 .

\section{Declarations}

Conflict of interest The authors have no conflicts of interest to declare.
Ethical Approval All procedures performed in studies involving human participants were in accordance with the ethical standards of the institutional and/or national research committee and with the 1964 Helsinki declaration and its later amendments or comparable ethical standards.

Research Involving Human and Animal Rights This article does not contain any studies with animals performed by any of the authors.

\section{References}

Adams, R. E., Boscarino, J. A., \& Figley, C. R. (2006). Compassion fatigue and psychological distress among social workers: A validation study. American Journal of Orthopsychiatry, 76(1), 103108. https://doi.org/10.1037/0002-9432.76.1.103

Andreasen, N. C., Carpenter, W. T., Jr., Kane, J. M., Lasser, R. A., Marder, S. R., \& Weinberger, D. R. (2005). Remission in schizophrenia: Proposed criteria and rationale for consensus. The American Journal of Psychiatry, 162(3), 441-449. https://doi.org/10. 1176/appi.ajp.162.3.441

Anthony, W. A. (1993). Recovery from mental illness: The guiding vision of the mental health service system in the 1990s. Psychosocial Rehabilitation Journal, 16(4), 11-23. https://doi.org/10. 1037/h0095655

Awa, W. L., Plaumann, M., \& Walter, U. (2010). Burnout prevention: A review of intervention programs. Patient Education and Counseling, 78(2), 184-190. https://doi.org/10.1016/j.pec.2009.04.008

Axelsson, M., Schønning, V., Bockting, C., Buysse, A., Desmet, M., Dewaaele, A., Giovazolias, T., Hannon, D., Kafetsios, K., Meganck, R., Ntani, S., Rutten, K., Triliva, S., Beveren, L. V., Vandamme, J., Øverland, S., \& Hensing, G. (2020). Lived experiences: A focus group pilot study within the MentALLY project of mental healthcare among European users. BMC Health Services Research, 20, 605. https://doi.org/10.1186/s12913-020-05454-5

Baker, E. K. (2003). Caring for ourselves: A Therapist's Guide to Personal and Professional Well-being. American Psychological Association.

Bearse, J. L., McMinn, M. R., Seegobin, W., \& Free, K. (2013). Barriers to psychologists seeking mental health care. Professional Psychology: Research and Practice, 44(3), 150-157. https://doi. org/10.1037/a0031182

Bride, B. E., Radey, M., \& Figley, C. R. (2007). Measuring compassion fatigue. Clinical Social Work Journal, 35(3), 155-163. https://doi. org/10.1007/s10615-007-0091-7

Cetrano, G., Tedeschi, F., Rabbi, L., Gosetti, G., Lora, A., Lamonaca, D., Manthorpe, J., \& Amaddeo, F. (2017). How are compassion fatigue, burnout, and compassion satisfaction affected by quality of working life? Findings from a survey of mental health staff in Italy. BMC Health Services Research, 17(1), 755. https://doi.org/ 10.1186/s12913-017-2726-x

Christodoulou, G., Ploumpidis, D., Christodoulou, N., \& Anagnostopoulos, D. (2012). The state of psychiatry in Greece. International Review of Psychiatry, 24(4), 301-306. https://doi.org/10.3109/ 09540261.2012 .691874

Clement, S., Schauman, O., Graham, T., Maggioni, F., Evans-Lacko, S., Bezborodovs, N., Morgan, C., Rüsch, N., Brown, J. S. L., \& Thornicroft, G. (2014). What is the impact of mental healthrelated stigma on help-seeking? A systematic review of quantitative and qualitative studies. Psychological Medicine, 45(01), 11-27. https://doi.org/10.1017/s0033291714000129

Cohen, J. (1988). Statistical power analysis for the behavioral sciences (2nd ed.). Lawrence Erlbaum. 
Corrigan, P. W., \& Rao, D. (2012). On the self-stigma of mental illness: Stages, disclosure, and strategies for change. The Canadian Journal of Psychiatry, 57(8), 464-469. https://doi.org/10.1177/ 070674371205700804

de Jacq, K., Norful, A. A., \& Larson, E. (2016). The variability of nursing attitudes toward mental illness: An integrative review. Archives of Psychiatric Nursing, 30(6), 788-796. https://doi.org/ 10.1016/j.apnu.2016.07.004

Ebrahimi, H., Namdar, H., \& Vahidi, M. (2012). Mental illness stigma among nurses in psychiatric wards of teaching hospitals in the north-west of Iran. Iranian Journal of Nursing and Midwifery Research, 17(7), 534-538.

Economou, M., Peppou, L. E., Kontoangelos, K., Palli, A., Tsaliagkou, I., Legaki, E.-M., Gournellis, R., \& Papageorgiou, C. (2019). Mental health professionals' attitudes to severe mental illness and its correlates in psychiatric hospitals of Attica: The role of workers' empathy. Community Mental Health Journal, 56(4), 614-625. https://doi.org/10.1007/s10597-019-00521-6

Economou, M., Peppou, L. E., Kontoangelos, K., Palli, A., Tsaliagkou, I., Legaki, E. M., Gournellis, R., \& Papageorgiou, C. (2020). Mental health professionals' attitudes to severe mental illness and its correlates in psychiatric hospitals of Attica: The role of workers' empathy. Community Mental Health Journal, 56(4), 614-625. https://doi.org/10.1007/s10597-019-00521-6

Evans, S., Huxley, P., Gately, C., Webber, M., Mears, A., Pajak, S., Medina, J., Kendall, T., \& Katona, C. (2006). Mental health, burnout and job satisfaction among mental health social workers in England and Wales. British Journal of Psychiatry, 188(1), 75-80. https://doi.org/10.1192/bjp.188.1.75

Figley, C. R. (1995). Compassion fatigue as secondary traumatic stress disorder: An overview. In C. R. Figley (Ed.), Compassion fatigue: Coping with secondary traumatic stress disorder in those who treat the traumatized (pp. 1-20). Brunner-Routledge.

Figley, C. R. (2002). Compassion fatigue: Psychotherapists' chronic lack of self-care. Journal of Clinical Psychology, 58(11), 14331441. https://doi.org/10.1002/jclp.10090

Flanagan, E. H., Miller, R., \& Davidson, L. (2009). "Unfortunately, we treat the chart": Sources of stigma in mental health settings. Psychiatric Quarterly, 80(1), 55-64.

Fontesse, S., Demoulin, S., Stinglhamber, F., \& Maurage, P. (2019). Dehumanization of psychiatric patients: Experimental and clinical implications in severe alcohol-use disorders. Addictive Behaviors, 89, 216-223. https://doi.org/10.1016/j.addbeh.2018.08.041

Freudenberger, H. (1974). Staff burnout. Journal of Social Issues, 30, 159-165. https://doi.org/10.1111/j.1540-4560.1974.tb00706.x

Glick, I. D., Zamora, D., Davis, J. M., Suryadevara, U., Goldenson, A., \& Kamis, D. (2020). Are patients with schizophrenia better off with lifetime antipsychotic medication? Journal of Clinical Psychopharmacology, 40(2), 145-148. https://doi.org/10.1097/ jcp.0000000000001171

Hamilton, S., Pinfold, V., Cotney, J., Couperthwaite, L., Matthews, J., Barret, K., Warren, S., Corker, E., Rose, D., Thornicroft, G., \& Henderson, C. (2016). Qualitative analysis of mental health service users' reported experiences of discrimination. Acta Psychiatrica Scandinavica, 134(Suppl 446), 14-22. https://doi.org/ 10.1111/acps. 12611

Holmqvist, R., \& Jeanneau, M. (2006). Burnout and psychiatric staff's feelings towards patients. Psychiatry Research, 145(2-3), 207213. https://doi.org/10.1016/j.psychres.2004.08.012

Hsiao, C. Y., Lu, H. L., \& Tsai, Y. F. (2015). Factors influencing mental health nurses' attitudes towards people with mental illness. International Journal of Mental Health Nursing, 24(3), 272-280. https://doi.org/10.1111/inm.12129

Joyce, O., \& Blessing, U. (2019). Affiliate stigma and compassion satisfaction amongst mental health service providers at a regional psychiatric hospital in Nigeria. Journal of Behavior
Therapy and Mental Health, 2(1), 30-39. https://doi.org/10. 14302/issn.2474-9273.jbtm-19-2854

Knaak, S., Christie, R., Mercer, S., \& Stuart, H. (2019). Harm reduction, stigma and the problem of low compassion satisfaction. Journal of Mental Health and Addiction Nursing, 3(1), e8-e21. https://doi.org/10.22374/jmhan.v3i1.37

Konstantinou, A.-K., Bonotis, K., Sokratous, M., Siokas, V., \& Dardiotis, E. (2018). Burnout evaluation and potential predictors in a Greek cohort of mental health nurses. Archives of Psychiatric Nursing, 32(3), 449-456. https://doi.org/10.1016/j.apnu.2018. 01.002

Kyriakidou, N., \& Triliva, S. (2018). The "constant tug-of-war" in mental health care in Greece. Mental Health Review Journal, 23(3), 121-130. https://doi.org/10.1108/MHRJ-11-2017-0050

Lauvrud, C., Nonstad, K., \& Palmstierna, T. (2009). Occurrence of post-traumatic stress symptoms and their relationship to professional quality of life (ProQoL) in nursing staff at a forensic psychiatric security unit: A cross-sectional study. Health and Quality of Life Outcomes. https://doi.org/10.1186/1477-7525-7-31

Laverdière, O., Kealy, D., Ogrodniczuk, J. S., Chamberland, S., \& Descôteaux, J. (2019). Psychotherapists' professional quality of life. Traumatology, 25(3), 208-215. https://doi.org/10.1037/ trm0000177

Lebowitz, M. S., \& Ahn, W. (2014). Effects of biological explanations for mental disorders on clinicians' empathy. Proceedings of the National Academy of Sciences, 111(50), 17786-17790. https://doi.org/10.1073/pnas.1414058111

Lee, J., Lim, N., Yang, E., \& Lee, S. M. (2011). Antecedents and consequences of three dimensions of burnout in psychotherapists: A meta-analysis. Professional Psychology: Research and Practice, 42(3), 252-258. https://doi.org/10.1037/a0023319

Linden, M., \& Kavanagh, R. (2011). Attitudes of qualified vs. student mental health nurses towards an individual diagnosed with schizophrenia. Journal of Advanced Nursing, 68(6), 1359-1368. https://doi.org/10.1111/j.1365-2648.2011.05848.x

Madianos, M. G., Economou, M., Peppou, L. E., Kallergis, G., Rogakou, E., \& Alevizopoulos, G. (2012). Measuring public attitudes to severe mental illness in Greece: Development of a new scale. European Journal of Psychiatry, 26, 55-67. https://doi.org/10. 4321/S0213-61632012000100006

Mangoulia, P., Koukia, E., Alevizopoulos, G., Fildissis, G., \& Katostaras, T. (2015). Prevalence of secondary traumatic stress among psychiatric nurses in Greece. Archives of Psychiatric Nursing, 29(5), 333-338. https://doi.org/10.1016/j.apnu.2015. 06.001

Mantelou, A., \& Karakasidou, E. (2019). The role of compassion for self and others, compassion fatigue and subjective happiness on levels of well-being of mental health professionals. Psychology, 10(3), 285-304. https://doi.org/10.4236/psych.2019.103021

Marder, S. R., \& Zito, M. F. (2018). Will I need to take these medications for the rest of my life? World Psychiatry, 17(2), 165-166. https://doi.org/10.1002/wps.20519

Maslach, C., \& Jackson, S. E. (1981). Maslach Burnout Inventory. Consulting Psychologists Press.

Maslach, C., \& Jackson, S. E. (1984). Burnout in organizational settings. Applied Social Psychology Annual, 5, 133-153.

Maslach, C., Jackson, S. E., \& Leiter, M. P. (1986). Maslach Burnout Inventory (3rd ed.). Consulting Psychologists Press.

Maslach, C., Jackson, S. E., \& Leiter, M. P. (1996). MBI: The Maslach Burnout Inventory Manual (3rd ed.). Consulting Psychologists Press.

Morse, G., Salyers, M. P., Rollins, A. L., Monroe-DeVita, M., \& Pfahler, C. (2012). Burnout in mental health services: A review of the problem and its remediation. Administration and Policy in Mental Health and Mental Health Services Research, 39(5), 341-352. https://doi.org/10.1007/s10488-011-0352-1 
O’Connor, K., Neff, D. M., \& Pitman, S. (2018). Burnout in mental health professionals: A systematic review and meta-analysis of prevalence and determinants. European Psychiatry, 53, 74-99. https://doi.org/10.1016/j.eurpsy.2018.06.003

Parcesepe, A. M., \& Cabassa, L. J. (2012). Public stigma of mental illness in the United States: A systematic literature review. Administration and Policy in Mental Health and Mental Health Services Research, 40(5), 384-399. https://doi.org/10.1007/ s10488-012-0430-z

Rachiotis, G., Syrgani, C., Symvoulakis, E. K., Dadouli, K., Papagiannis, D., Gourgoulianis, K. I., \& Candilis, P. J. (2020). Burnout and associated factors among Greek substance use disorder treatment providers during economic crisis. Archives of Environmental \& Occupational Health. https://doi.org/10.1080/19338244.2020. 1842311

Ray, S. L., Wong, C., White, D., \& Heaslip, K. (2013). Compassion satisfaction, compassion fatigue, work life conditions, and burnout among frontline mental health care professionals. Traumatology, 19(4), 255-267. https://doi.org/10.1177/1534765612471144

Reavley, N. J., Mackinnon, A. J., Morgan, A. J., \& Jorm, A. F. (2013). Stigmatising attitudes towards people with mental disorders: A comparison of Australian health professionals with the general community. Australian \& New Zealand Journal of Psychiatry, 48(5), 433-441. https://doi.org/10.1177/0004867413500351

Rüsch, N., Angermeyer, M. C., \& Corrigan, P. W. (2005). Mental illness stigma: Concepts, consequences, and initiatives to reduce stigma. European Psychiatry, 20(8), 529-539. https://doi.org/10. 1016/j.eurpsy.2005.04.004

Schulze, B. (2007). Stigma and mental health professionals: A review of the evidence on an intricate relationship. International Review of Psychiatry, 19(2), 137-155. https://doi.org/10.1080/09540 260701278929

Singh, J., Karanika-Murray, M., Baguley, T., \& Hudson, J. (2020). A systematic review of job demands and resources associated with compassion fatigue in mental health professionals. International Journal of Environmental Research and Public Health, 17(19), 6987. https://doi.org/10.3390/ijerph17196987

Smith, J. D., Mittal, D., Chekuri, L., Han, X., \& Sullivan, G. (2017). A comparison of provider attitudes toward serious mental illness across different health care disciplines. Stigma and Health, 2(4), 327-337. https://doi.org/10.1037/sah0000064

Solmi, M., Granziol, U., Danieli, A., Frasson, A., Meneghetti, L., Ferranti, R., Zordan, M., Salvetti, B., Conca, A., Salcuni, S., \& Zaninotto, L. (2020). Predictors of stigma in a sample of mental health professionals: Network and moderator analysis on gender, years of experience, personality traits, and levels of burnout. European Psychiatry. https://doi.org/10.1192/j.eurpsy.2019.14

Stalker, C., \& Harvey, C. (2002). Professional Burnout in Social Service Organizations: A review of theory, research, and prevention (pp. 1-56, Report). Wilfrid Laurier University, Partnerships for Children and Families Project (Finding a Fit: Family Realities and Service Responses Series).

Stamm, B. H. (2002). Measuring compassion satisfaction as well as fatigue: Developmental history of the compassion satisfaction and fatigue test. In C. R. Figley (Ed.), Treating compassion fatigue (pp. 107-119). Brunner-Routledge.

Stamm, B. H. (2005). The ProQOL manual: The Professional Quality of Life Scale: Compassion satisfaction, Burnout and compassion fatigue/secondary trauma scales. Sidran Press. https://doi.org/10. $1037 /$ tra0000263

Stamm, B. H. (2010). The concise ProQOL manual (2nd ed.). ProQOL. org.

Stuber, J. P., Rocha, A., Christian, A., \& Link, B. G. (2014). Conceptions of mental illness: Attitudes of mental health professionals and the general public. Psychiatric Services, 65(4), 490-497. https://doi.org/10.1176/appi.ps.201300136
Summers, R. F., Gorrindo, T., Hwang, S., Aggarwal, R., \& Guille, C. (2020). Well-being, burnout, and depression among North American psychiatrists: The state of our profession. American Journal of Psychiatry, 177(10), 955-964. https://doi.org/10.1176/appi.ajp. 2020.19090901

Świtaj, P., Chrostek, A., Grygiel, P., Wciórka, J., \& Anczewska, M. (2016). Exploring factors associated with the psychosocial impact of stigma among people with schizophrenia or affective disorders. Community Mental Health Journal, 52(3), 370-378. https://doi. org/10.1007/s10597-014-9800-1

Thornicroft, G. (2007). Most people with mental illness are not treated. The Lancet, 370(9590), 807-808. https://doi.org/10.1016/s01406736(07)61392-0

Tirgari, B., Azizzadeh Forouzi, M., \& Ebrahimpour, M. (2018). Relationship between posttraumatic stress disorder and compassion satisfaction, compassion fatigue, and burnout in Iranian psychiatric nurses. Journal of Psychosocial Nursing and Mental Health Services, 57(3), 39-47. https://doi.org/10.3928/02793695-20181 023-02

Triliva, S., Fragkiadaki, E., \& Balamoutsou, S. (2013). Forging partnerships for mental health: The case of a prefecture in crisis ravaged Greece. European Journal of Psychotherapy and Counseling, 15(4), 375-390. https://doi.org/10.1080/13642537.2013.849275

Triliva, S., Ntani, S., Giovazolias, T., Kafetsios, K., Axelsson, M., Bockting, C., Buysse, A., Desmet, M., Dewaele, A., Hannon, D., Haukenes, I., Hensing, G., Meganck, R., Rutten, K., Schønning, V., Van Beveren, L., Vandamme, J., \& Øverland, S. (2020). Healthcare professionals' perspectives on mental health service provision: A pilot focus group study in six European countries. International Journal of Mental Health Systems, 14, 16. https:// doi.org/10.1186/s13033-020-00350-1

Valery, K.-M., \& Prouteau, A. (2020). Schizophrenia stigma in mental health professionals and associated factors: A systematic review. Psychiatry Research. https://doi.org/10.1016/j.psychres.2020. 113068

van Boekel, L. C., Brouwers, E. P. M., van Weeghel, J., \& Garretsen, H. F. L. (2013). Stigma among health professionals towards patients with substance use disorders and its consequences for healthcare delivery: Systematic review. Drug and Alcohol Dependence, 131(1-2), 23-35. https://doi.org/10.1016/j.drugalcdep.2013.02. 018

Wahl, O., \& Aroesty-Cohen, E. (2010). Attitudes of mental health professionals about mental illness: A review of the recent literature. Journal of Community Psychology, 38(1), 49-62. https://doi.org/ 10.1002/jcop. 20351

Whitley, R., Palmer, V., \& Gunn, J. (2015). Recovery from severe mental illness. CMAJ: Canadian Medical Association Journal, 187(13), 951-952. https://doi.org/10.1503/cmaj.141558

Xie, W., Wang, J., Okoli, C. T. C., He, H., Feng, F., Zhuang, L., Tang, P., Zeng, L., \& Jin, M. (2020). Prevalence and factors of compassion fatigue among Chinese psychiatric nurses. Medicine, 99(29), e21083. https://doi.org/10.1097/md.0000000000021083

Zaninotto, L., Rossi, G., Danieli, A., Frasson, A., Meneghetti, L., Zordan, M., Tito, P., Salvetti, B., Conca, A., Ferranti, R., Salcuni, S., \& Solmi, M. (2018). Exploring the relationships among personality traits, burnout dimensions and stigma in a sample of mental health professionals. Psychiatry Research, 264, 327-333. https://doi.org/10.1016/j.psychres.2018.03.076

Zolezzi, M., Alamri, M., Shaar, S., \& Rainkie, D. (2018). Stigma associated with mental illness and its treatment in the Arab culture: A systematic review. The International Journal of Social Psychiatry, 64(6), 597-609. https://doi.org/10.1177/0020764018789200

Publisher's Note Springer Nature remains neutral with regard to jurisdictional claims in published maps and institutional affiliations. 